"نشريه علوم زراعى ايران"

جلد بيست و يكم، شماره ع، زمستان يوسا

اثر تنش كمبود روى بر الكوى بيان زنهاى رمز كننده فاكتورهاى رونويسى bZIP4،

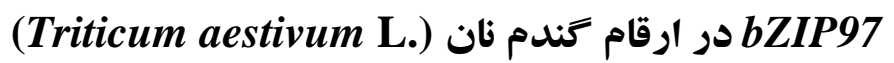

Effect of Zn deficiency stress on expression pattern of genes encoding bZIP4, bZIP79 and bZIP97 transcription factors in bread wheat

(Triticum aestivum L.) cultivars

$$
\text { مينا اختيارى' و بابك عبد الهى مندولكانى r }
$$

جكيده

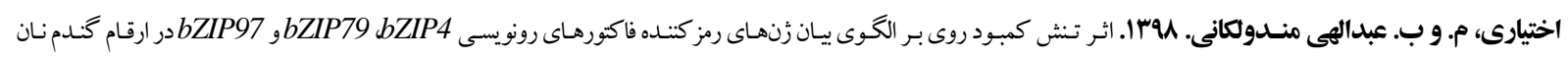
(Triticum aestivum L.)

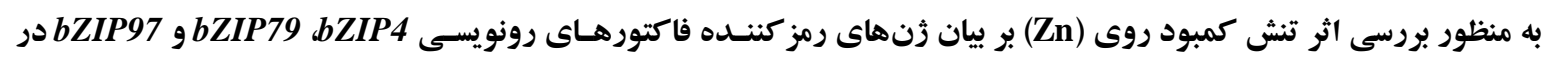

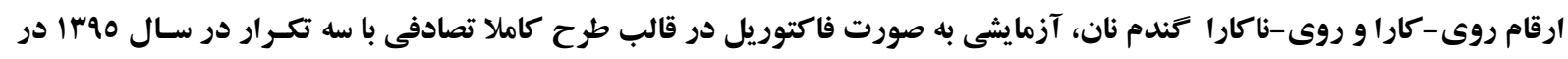

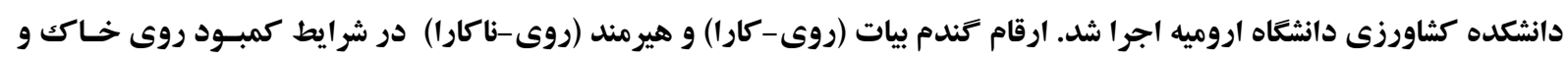

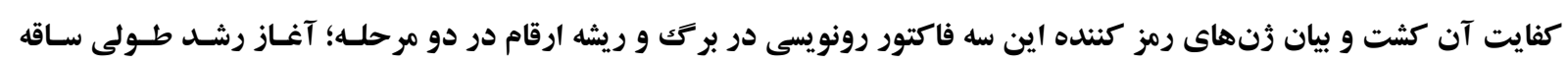

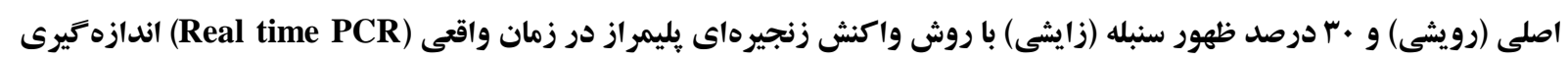

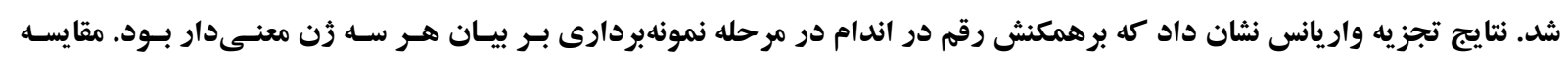

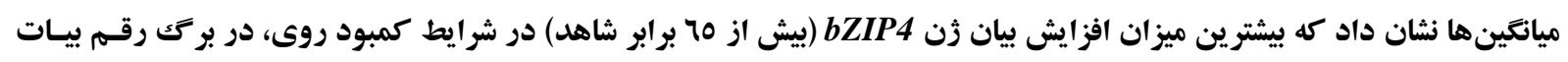

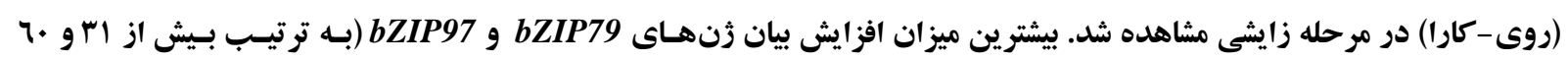

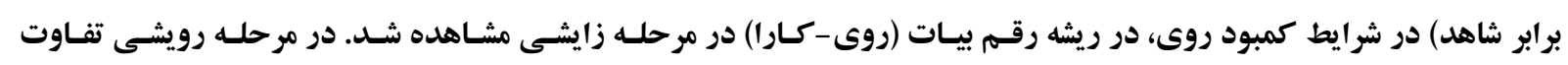

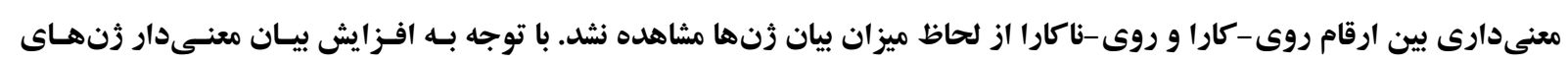

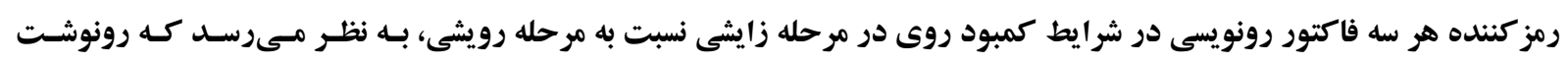

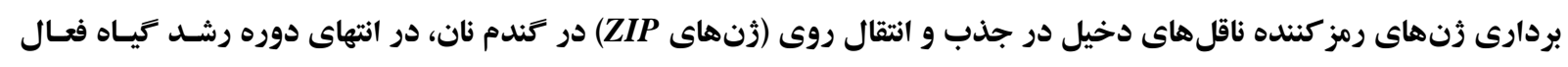

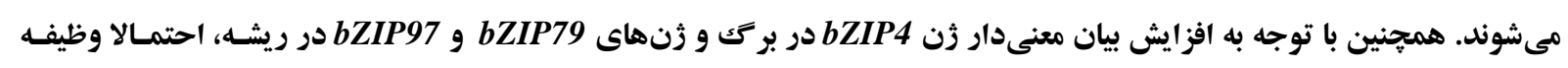

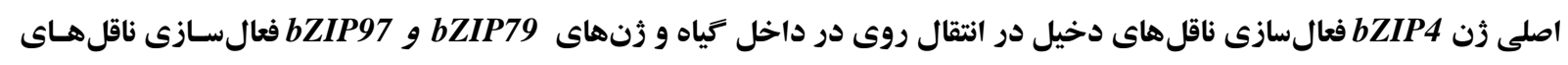

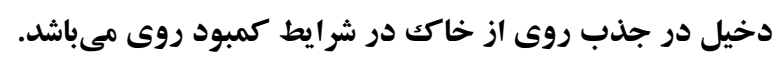

وازههاى كليدى: بيان زن، فاكتور رونويسى bZIP، كمبود روى، كندم نان و واكنش زنجيرهاى بليمراز در زمان واقعى.

اين مقاله مستخرج از يايان نامه كارشناسى ارشد نگكارنده اول مى باشد.

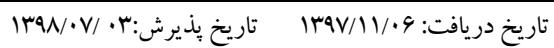

1- إنشجوى كارشناسى ارشد دانشكده كشاورزى دانشخاه اروميه

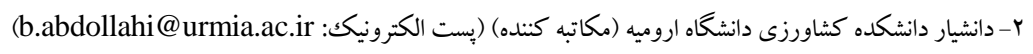


(Zn) بــه دليــل نقــش آن در ســـتز هورمونهـــاى (Zn)

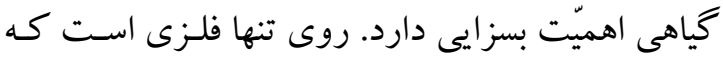
در تمـامى شـش گـروه آنـزيمهـا (اكسـيدوردو كتازها، ترانسفرازها، هيدروليزها، ليازها، ايزومرازها، و ليكازهـا) وجود دارد (Coleman, 1998). در تغذيه انسـان، كمبـود

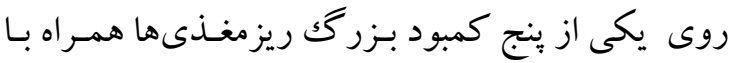

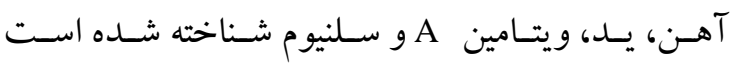
(Welch and Graham, 1999)

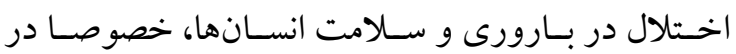
زنان و نوزادان و در خانوادههـاى كـم در آمــد مى شـود (Mason and Garcia, 1993)

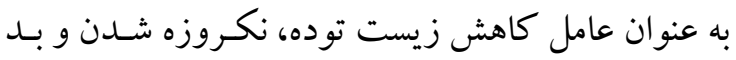

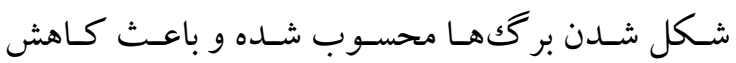

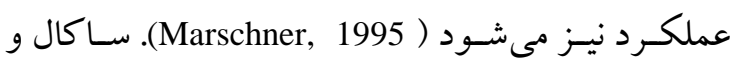

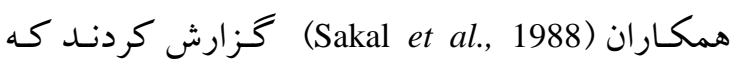
هرجه حاصلخيزى خاك بيشتر باشد، ميزان تخليه روى

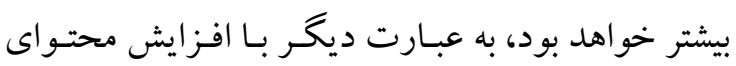

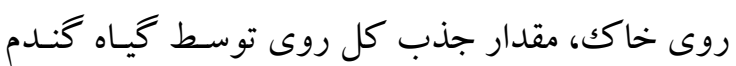

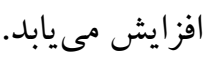

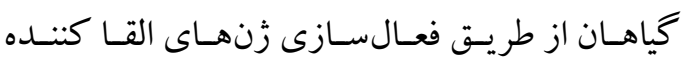

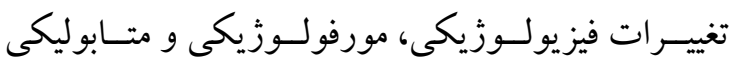
در اندامهاى خود با تنشهاى محيطى مقابله مسى كنــد.

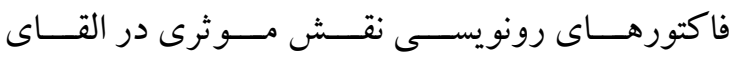

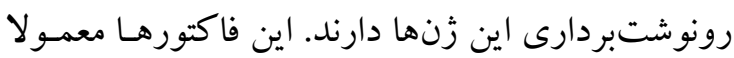

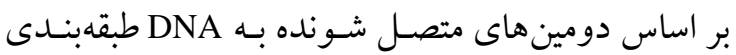
مىشوند. از جمله ايـن فاكتورهـاى رونويسى، خـانو اده

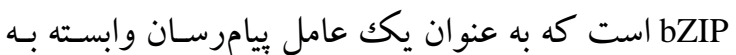
هورمـون آبسـزيكك اسـيد بــراى اولـين بــار در خيـاه آرابيدويسيس شناسايى شده است (Alves et al., 2013).

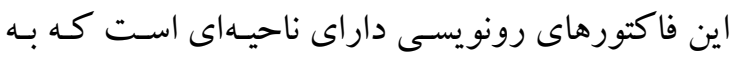
D و موتيـف Leucin zipper متصـل مسى شـــود

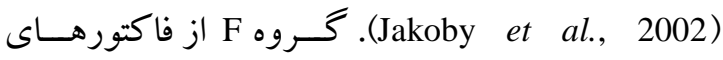
رونويسى bZIP باعث القاى بيان زنهاى ZIP در شـر ايط

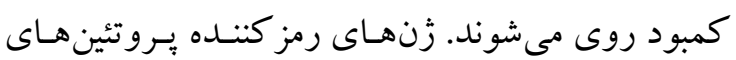

\section{مقدمه}

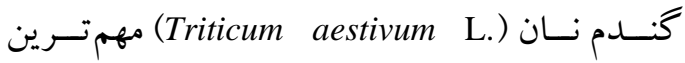
محصـول زراعسى در بــين غـلات بـه شــمار مسىرود Kasirajan et al., 2013) كالرى مورد نياز جمعيت جهان را تـامين مسىكند و در اير ان منبع اصلى كربوهيدرات به شمار مسرودد. سـازمان

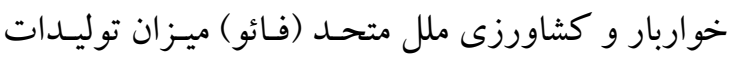

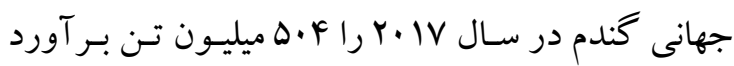

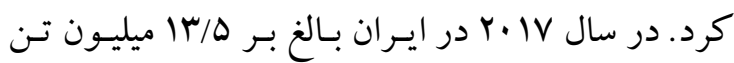

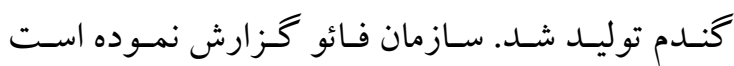

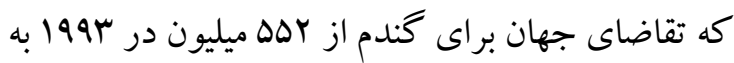

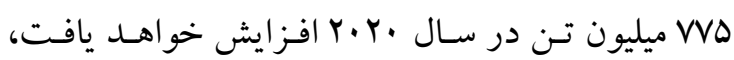

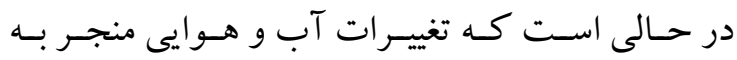

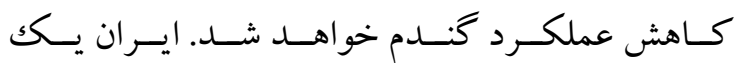

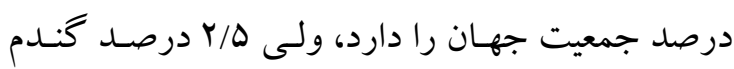
جهان را مصرف مى كند :Ahmadi-Niari et al., 2013 .Bahari et al., 2013)

تنش هاى محيطى مهم ترين عوامـل كـاهش دهنــده

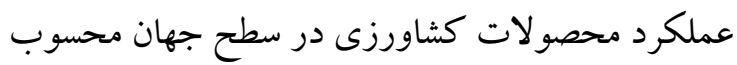
مىشـوند (Nakabayashi and Saito, 2015). از جملـه

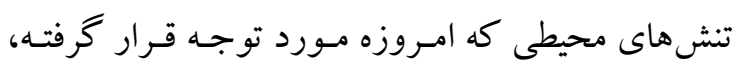

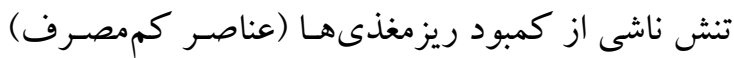
است. عناصر كممصرف سوخت و ساز مـواد غـذايى را

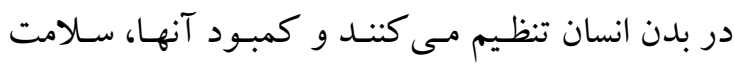

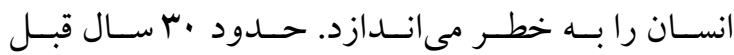
سوء تغذيه فقط مفهومى معادل كمبود دريافت يـروتئين

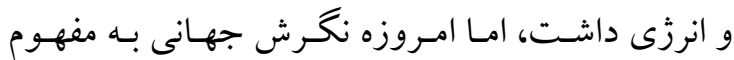

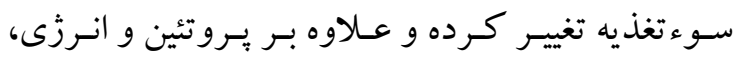

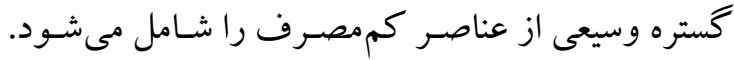
بعلاوه، ريزمغذىها از عناصر ضرورى مورد نيعى نياز كياهان

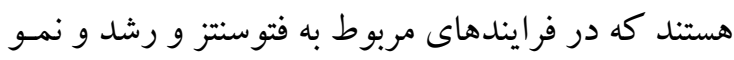

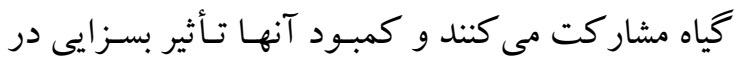

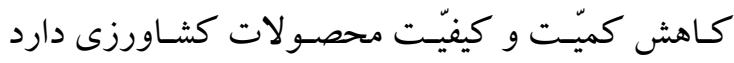

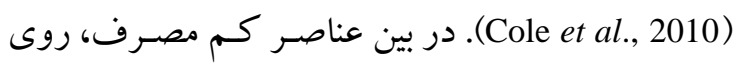




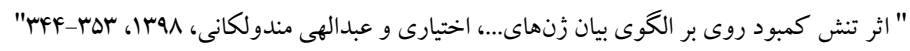

رمز كنتده اين سـه فـاكتور رونويسى در بـرك و ريشـه

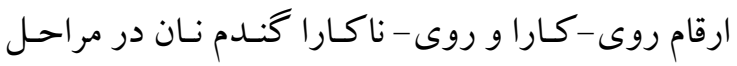
مختلف رشد در شرايط كمبود روى اجرا شد.

\section{مواد و روشها}

اين تحقيق به صورت فاكتوريل در قالب طرح كاملا تصادفى با سه تكرار در سال هوسا در كلخانه تحقيقاتى دانشكده كشاورزى دانشكاه اروميه اجرا شد. بذور ارقام كنــدم بيـات (روى -كــار) و هيرمنــد (روى - ناكــارا) در (Baghban-Tabiat and Rasouli-Sadaghiani, 2012) دو سطح روى صفر (كمبـود روى) و ه (كفايـت روى) ميلى كرم روى در كيلو گرم خاكى كشت شـدند. خـاكك تهيسه شـده از يـكك بسـتر شـنى در منطقـه شبسـتر تبريـز

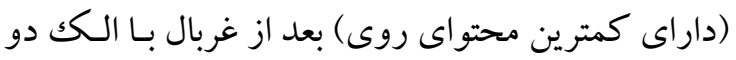

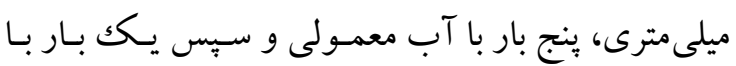
آب دوبـار تقطيـر شسته شـــ تـا ميسزان روى خــاكك بـــ كمترين حد ممكن برسد. قبل از كشت، آزمايش تجزيه خاكك انجام شد تـا از كمبـود روى آن اطمينـان حاصـل شود (جدول (). سيس مواد غذايى مورد نياز (جدول r) با خاكك مخلوط شد. در هريكك از كلدانهاى يلى اتيلنى

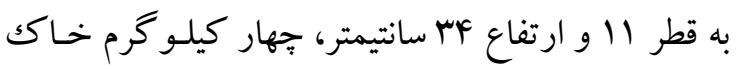
ريخته و بذور ضدعفونى شده (بـا الكـل ·V درصـد) در آن كاشته شدند. علاوه بر مواد غذايى، به خاكك نيمى از كلدانها ينج ميلى كرم در كيلو گرم خاكك عنصـر روى

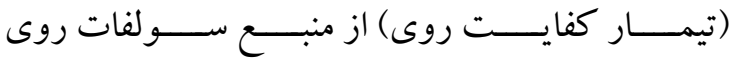
افزوده شـــ. در طـول فصـل بـه منظـور $\left(\mathrm{ZnSO}_{4} .7 \mathrm{H}_{2} \mathrm{O}\right)$ جلو گيرى از آلودگى روى، از آب دو بـار تقطيـر بـراى آبيارى كلدانهـا در حـــ ظرفيـت زراعـى اسـتفاده شـد.
ZIP در جـــب روى از محـــط رشـــ بـهـ سيتويلاســم ســلولهــاى ريشــهاى و انتقــال آن در داخــل كيــاه دخالت دارند. در شرايط طبيعى يونهاى Zn بـ لـه ناحيـه غنسى از سيسـتئين -هيسـتيدين ايسن فاكتورهـا متصـل و آنها را غير فعال مسىسـازند. بـه محسض كـاهش غلظت

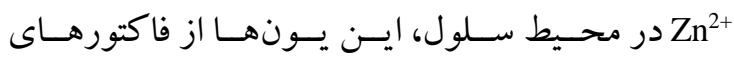
رونويسى جدا شده و اين فاكتورها به تـوالىهـاى ياســخ دهنده به روى در زُنهاى ZIP متصل و باعث رونويسى آنها مىشوند (Maser et al., 2001). ايونس و همكـاران (Evens et al., 2017) رونويسىى bZIP و زنهـاى ZIP را در پاسـخ بـه كمبـود روى در گياه كندم نـان بررسى كردنـد. در ايسن تحقيـق بيـان جهـار زن bZIPF4- bZIPF4-7DL، bZIPF1-7DL 7AL و مZIPF3b-7BL مطالعسه شـــ ايسن زنهـا تحست شر ايط كمبـود روى در ريشـه و انسامهاى هـوايى كيـاه

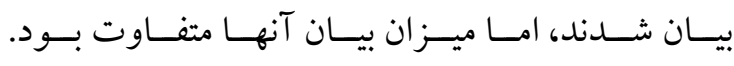

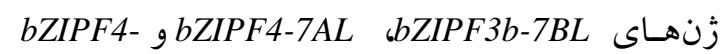
7DL بيشترين تغيير در الكوى بيان را (در ريشه و شـاخه) در شرايط كمبـود روى نشـان دادنـلد، امـا زن - bZIPF1 7DL در باسخ به كمبود روى بيان كندترى داشـت. ايسن

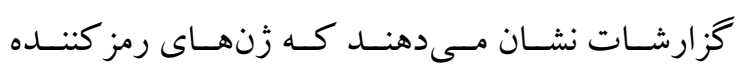
فاكتورهـاى رونويسىى bZIP در تسنش كمبـود روى در كياهان نيز همانند ساير تنش هاى زنده و غير زنسـده نقـش

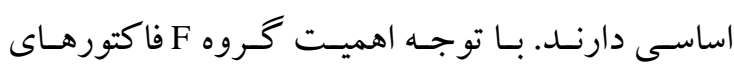

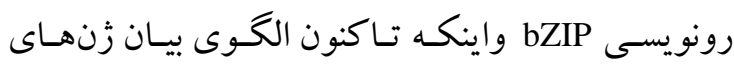

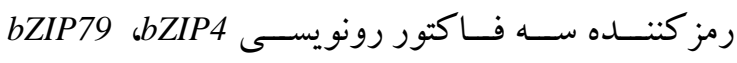
و bZIP97 در گندم نان در شـر ايط كمبـود روى مطالعـه نشده است، اين تحقيـق بـا هـدف بررسى بيـان زنهـاى

جدول ا- مشخصات فيزيكى و شيميايى خاكك مورد استفاده در آزمايش

Table 1. Physical and chemical properties of soil used in the experiment

\begin{tabular}{|c|c|c|c|c|c|c|c|c|c|c|}
\hline شن & سيلت & رس & روى & يتاسيم & فسفر & نيتروزن & ماده آلى & آهك & & شورى \\
\hline $\begin{array}{c}\text { Sand } \\
(\%)\end{array}$ & $\begin{array}{l}\text { Silt } \\
(\%)\end{array}$ & $\begin{array}{l}\text { Clay } \\
(\%)\end{array}$ & $\begin{array}{c}\mathrm{Zn} \\
\left(\mathrm{mg} \cdot \mathrm{kg}^{-1}\right)\end{array}$ & $\begin{array}{c}\mathrm{K} \\
\left(\mathrm{mg} \cdot \mathrm{kg}^{-1}\right)\end{array}$ & $\begin{array}{c}\mathrm{P} \\
\left(\mathrm{mg} \cdot \mathrm{kg}^{-1}\right)\end{array}$ & $\begin{array}{l}\mathrm{N} \\
(\%)\end{array}$ & $\begin{array}{c}\text { Organic matter } \\
(\%)\end{array}$ & $\begin{array}{c}\mathrm{CaCO} 3 \\
(\%)\end{array}$ & $\begin{array}{l}\text { اسيديته } \\
\text { pH }\end{array}$ & $\begin{array}{c}\text { Ec } \\
\left(\text { mmohs.cm }{ }^{-1}\right)\end{array}$ \\
\hline 96 & 1 & 3 & 0.15 & 9.4 & 2.5 & 0.61 & 0.69 & 9 & 7.8 & 1.19 \\
\hline
\end{tabular}




$$
\begin{aligned}
& \text { "نشريه علوم زراعى ايران"، جلد بيست و يكم، شماره أ، زمستان هوسا } \\
& \text { جدول r- تر كيب محلول غذايى مورد استفاده در آزمايش }
\end{aligned}
$$

\begin{tabular}{|c|c|c|}
\hline $\begin{array}{c}\text { تركيبات } \\
\text { Ingredients }\end{array}$ & $\begin{array}{c}\text { مقدار } \\
\text { Amount }\left(\mathrm{ml}^{\prime} \mathrm{kg}^{-1}\right)\end{array}$ & $\begin{array}{c}\text { غلظت } \\
\left.\text { Concentration (g. } \mathrm{l}^{-1}\right)\end{array}$ \\
\hline $\mathrm{K}_{2} \mathrm{SO}_{4} / \mathrm{KH}_{2} \mathrm{PO}_{4}$ & 3 & $48.407 / 30.242$ \\
\hline $\mathrm{NH}_{4} \mathrm{NO}_{3} / \mathrm{CaCl}_{2} .2 \mathrm{H}_{2} \mathrm{O}$ & 1 & $93 / 147.016$ \\
\hline $\mathrm{MgSO}_{4} .7 \mathrm{H}_{2} \mathrm{O}$ & 1 & 20.5 \\
\hline $\mathrm{MnSO}_{4} \cdot \mathrm{H}_{2} \mathrm{O} / \mathrm{Na}_{2} \mathrm{MoO}_{4} .2 \mathrm{H}_{2} \mathrm{O} / \mathrm{CuSO}_{4} .5 \mathrm{H}_{2} \mathrm{O} / \mathrm{H}_{3} \mathrm{BO}_{3}$ & 2 & $7.5 / 0.083 / 1.05 / 0.33$ \\
\hline $\mathrm{ZnSO}_{4} .7 \mathrm{H}_{2} \mathrm{O}$ & 1.67 & 13.14 \\
\hline
\end{tabular}

Table 2. Composition of the nutrient solution used in the experiment

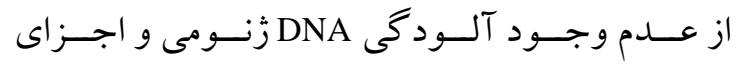

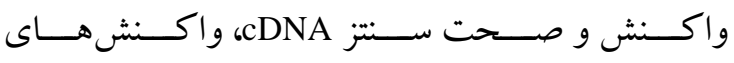

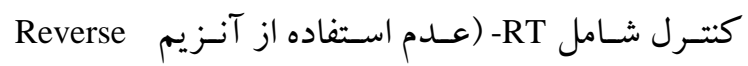

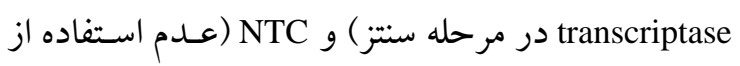

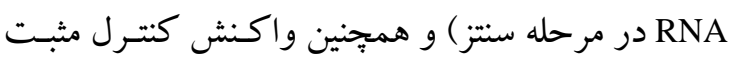

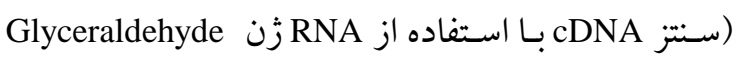
3-phosphate dehydrogenase

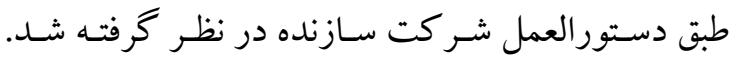

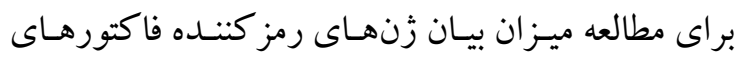

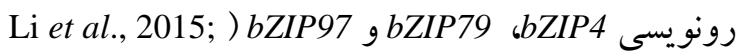
Evens et al., 2017 آنهـا از بايخــاه اطلاعـاتى Ensemble كنــدم اسـتخراج

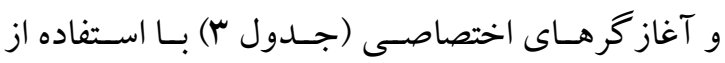

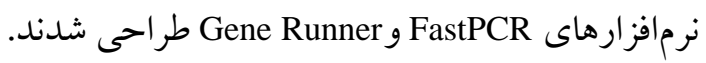

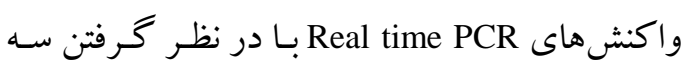

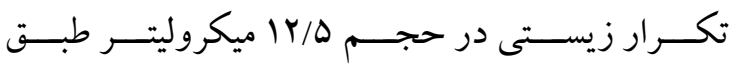

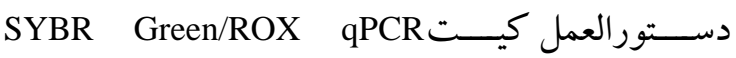

بــراى جلـو گيرى از كمبـود نيتـروزن، محلـول نيتـرات

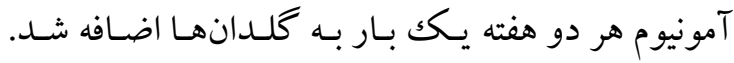
جهت مطالعه بيان زن، نمونهبردارى در دو مرحله؛ بهو آغـاز

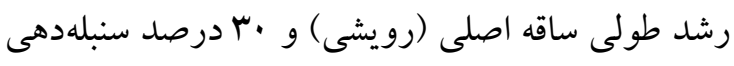

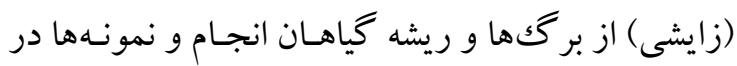
داخل نيتروزن مايع به فريزر • •^- درجه سانتيخر اد منتقـل

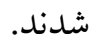
استخراج RNA از بر گك و ريشه گياهان با اسـتفاده از

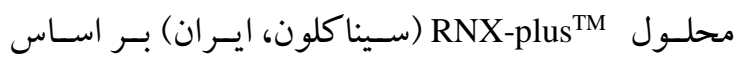
دستو رالعمل شركت سازنده با كمى تغييرات انجام شــــ كميت و كيفيت RNA بـا اسـتفاده از دستخاه نـانودراب و الكتروفورز زل آكارز يـك درصــ (Thermo, USA) تعيين شد. جهت سنتز cDNA از كيت RevertAid First (Fermentas, Germany) Strand cDNA Synthesis

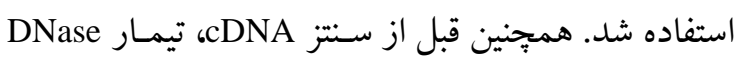

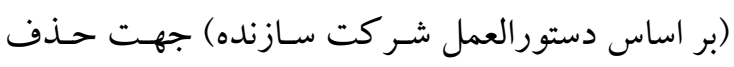

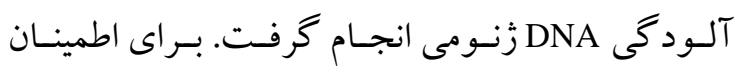

جدول r- مشخصات آغاز گرهاى مورد استفاده در واكنشهاى Real Time PCR

\begin{tabular}{|c|c|c|c|c|}
\hline 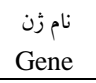 & $\begin{array}{c}\text { شماره دسترسى } \\
\text { Accession number }\end{array}$ & $\begin{array}{c}\text { توالى آغازگر } \\
\text { Primer sequence }\end{array}$ & $\begin{array}{c}\text { Annealing temperature }\left({ }^{\circ} \mathrm{C}\right) \\
\text { Alis }\end{array}$ & $\begin{array}{c}\text { طول محصول } \\
\text { Amplicon length (bp) } \\
\end{array}$ \\
\hline bzip97 & TRIAE_CS42_5BS_TGACv1_423566_AA1379610 & $\begin{array}{l}\text { F: agaacgtcgatttggttctgg } \\
\text { R: cgatagttctcatctgcattcctg }\end{array}$ & 60 & 126 \\
\hline bzip4 & TRIAE_CS42_1AL_TGACv1_001373_AA0029470 & $\begin{array}{l}\text { F: ctgcttcaacaatggcaactc } \\
\text { R: tcatcgaacctgtaatccgcag }\end{array}$ & 60 & 129 \\
\hline bzip79 & TRIAE_CS42_3B_TGACv1_221777_AA0749730 & $\begin{array}{l}\text { F: gaggagaatctagcttgttggcac } \\
\text { R: tacacgctaggaactcatcgaagc }\end{array}$ & 60 & 87 \\
\hline Actin3 & KX533928 & $\begin{array}{l}\text { F: gacgcacaacaggtatcgtgttg } \\
\text { R: agcgaggtcaagacgaaggatg }\end{array}$ & 60 & 107 \\
\hline
\end{tabular}

Table 3. Characteristics of the primers used in Real time PCR reactions 


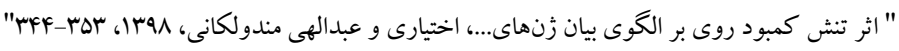

مقايسه ميانگين برهمكنش بافت در رقـم در مرحلـه

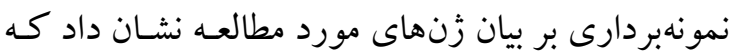
در شرايط كمبود روى بيشترين ميزان افزايش بيـان زن bZIP4

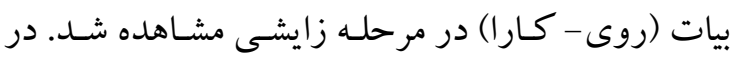
ريشه همين رقم و در بركى رقم هيرمنــ (روى - ناكـارا)

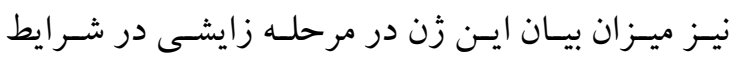

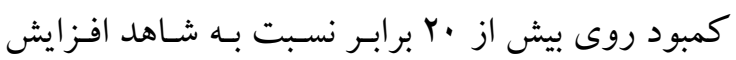

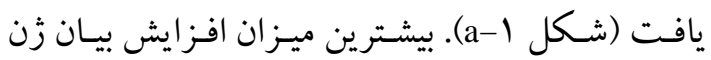

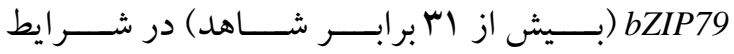
كمبود روى، در ريشه رقم بيات (روى-كارا) در مرحلـه

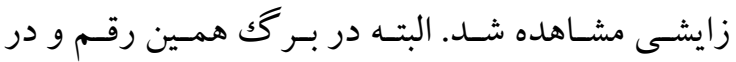
ريشه رقم هيرمنــ (روى-ناكـارا) نيـز در همـين مرحلـه

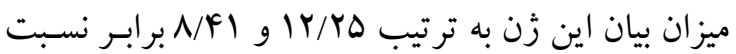

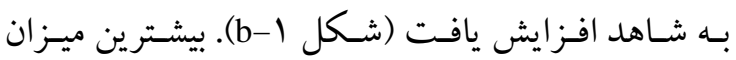
افزايش بيـان زن bZIP97 (بيش از •9 برابـر شـاهد) در

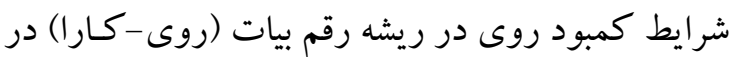

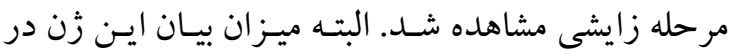

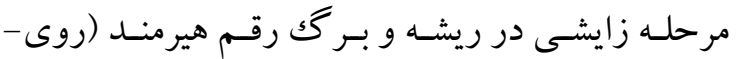

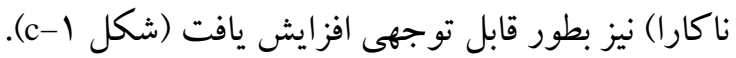
در مرحلــه رويشــى تفـــاوت معنـــدارى بــين ارقــام

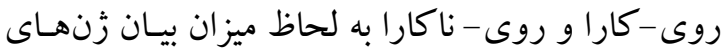

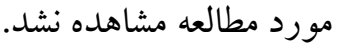

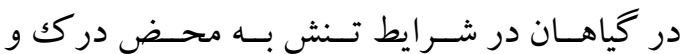
تشخيص تغييرات درون سـلولى، مسـيرهاى ييـام رسـانى

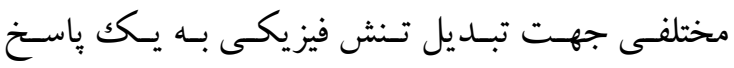
بيوشيميايى مناسب شـروع شـده و هريـك از آنها بيـان

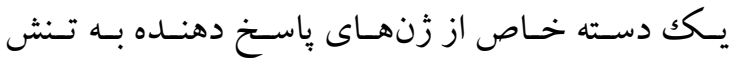

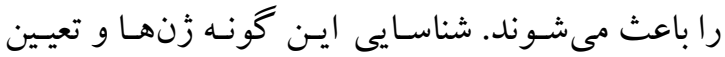

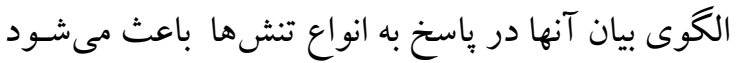

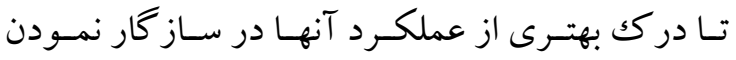

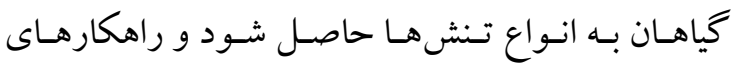

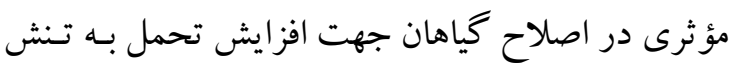
شناسـيى شـود (Khavarinejad and Babajanov 2011).
(Fermentas, Germany) Maser Mix (Rotor-Gene 6000, Qiagene, USA) Rotor-Gene Q انجام شد. از زن اكتين به عنوان زن مرجع در واكنشهـا

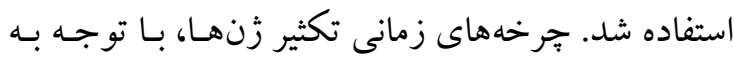

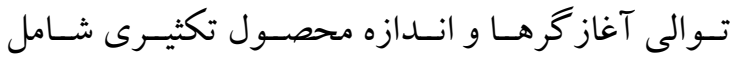

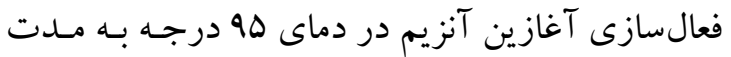

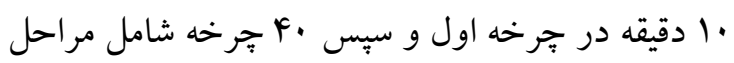
واسرشتسازى در دماى هو درجه سانتى گر اد بـه مـدات

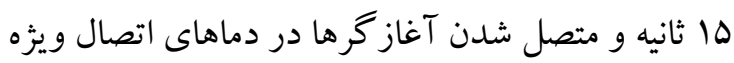

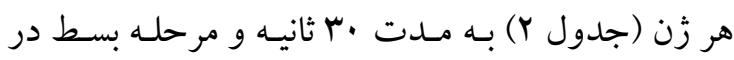

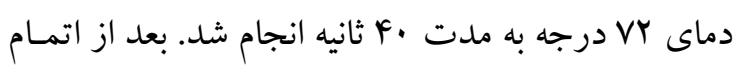

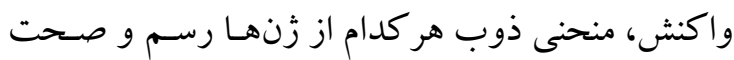

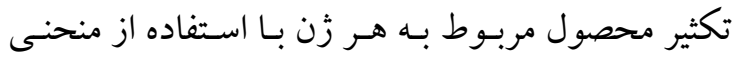

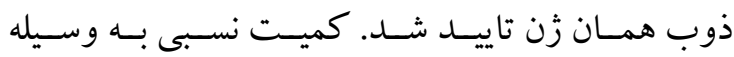

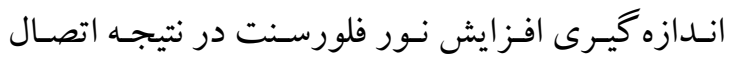

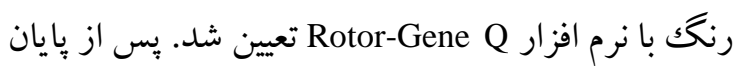
واكنشها، مقدار حد آستانه بـه گونسهاى در نظر كرفتـه شد كه علائم فلورسنت را در فاز نمايى قطع كند. بعد از

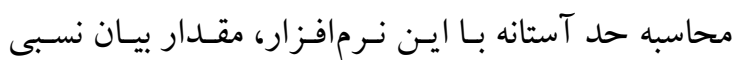
زنهـاى مـورد نظـر در گياهـان تيمـار شــه نسـبت بـهـ شـاهد بــا اسـتفاده از روش $\Delta \Delta C T$ محاسـبه شــد. بــه

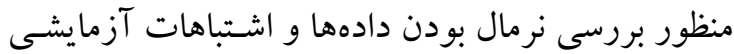

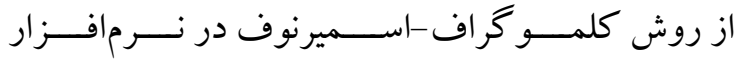
MINITAB (نســخه 19) و بــــاى تجزيــه واريــانس از

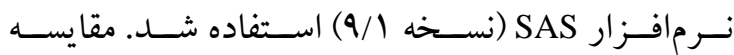

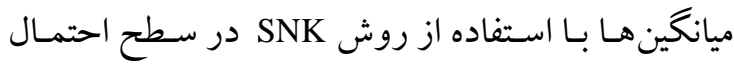

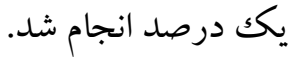

\section{نتايج و بحث}

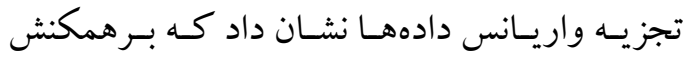

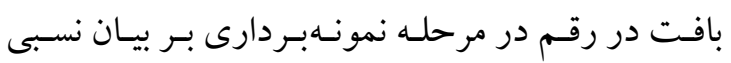

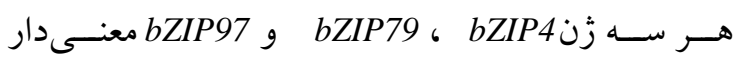
بـود، بنـابر اين مقايسـه ميـانگين ايسن بـرهمكنش ونس انجـام كرفت. 
اهميت گ FروF از فاكتورهاى رونويسى bZIP و زنهـاى

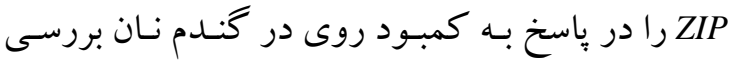

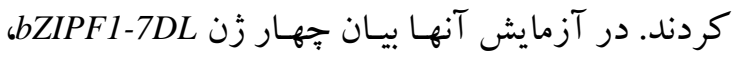
bZIPF4-7AL، bZIPF4-7DL مطالعه قرار گرفت. اين زنها در شرايط كمبود روى در

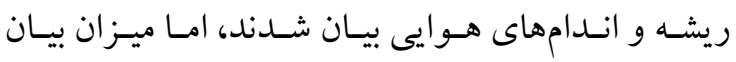
آنها متفـاوت بـود. زنهـاى bZIPF4- bZIPF3b-7BL

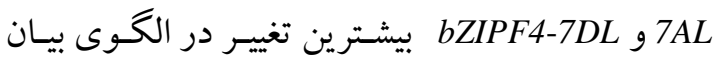

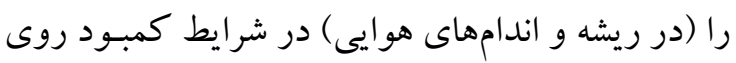

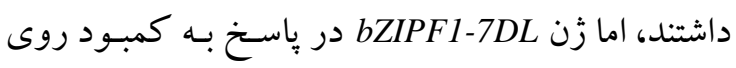

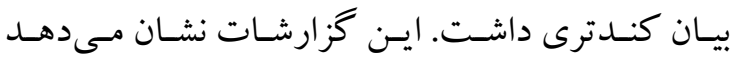

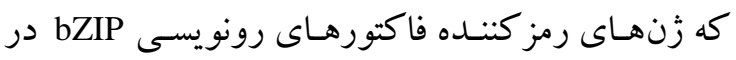

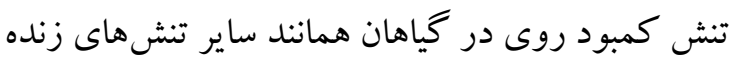

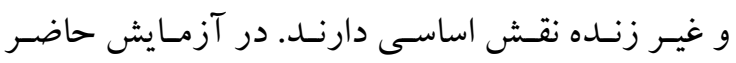

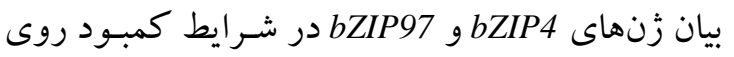

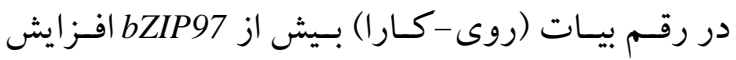

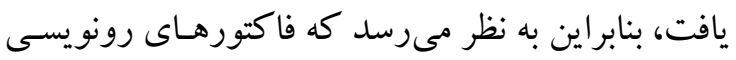

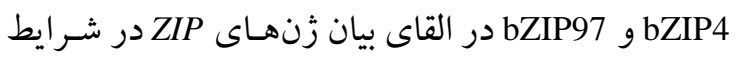

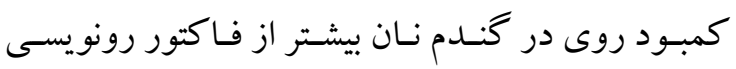

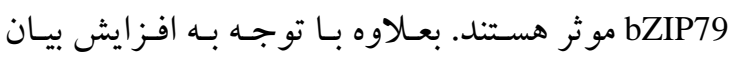

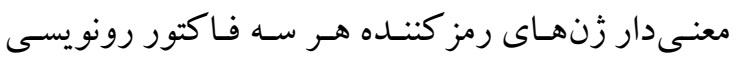

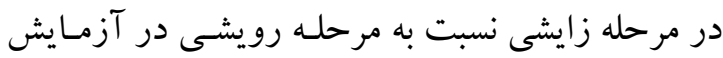

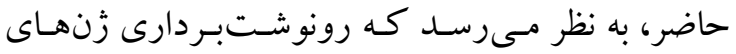

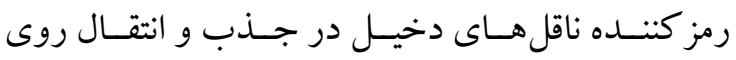

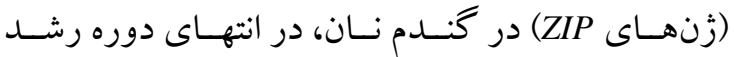

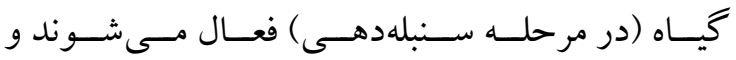
روى موجود را بعد از جذب به دانه انتقال مسيدهنـد. بـا

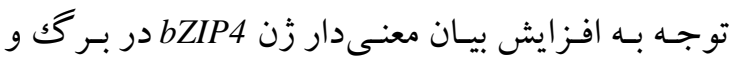

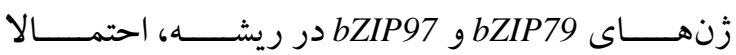

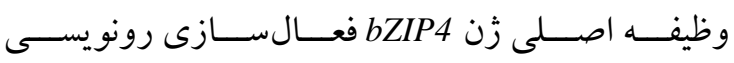

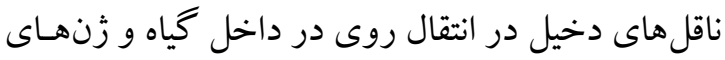

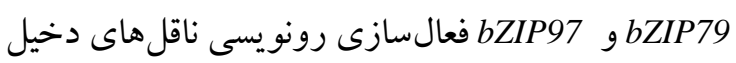

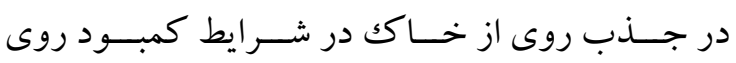
مىباشد.

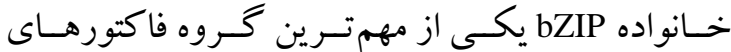
رونويسى هستند كه در رونوشت بـردارى تعـداد زيـادى

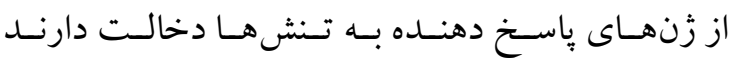

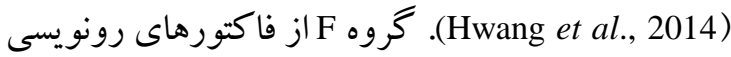

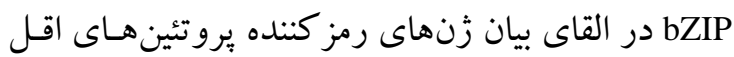

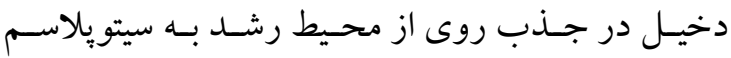

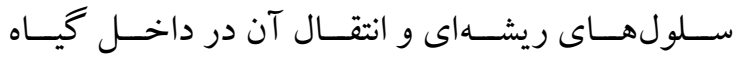

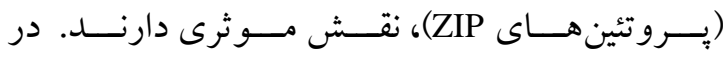

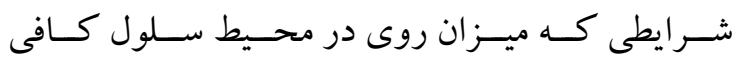
باشد، يونهاى Zn به ناحيه غنى از سيستئين -هيستيدين

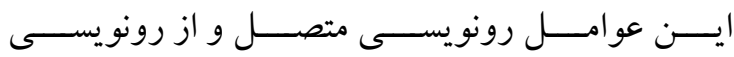
آنها جلو گيرى مى كنند. به محض كـاهش غلظت

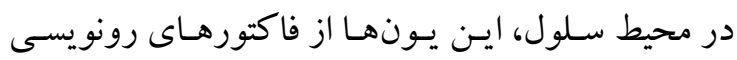

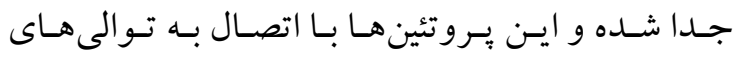

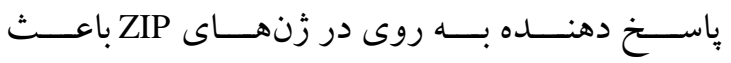

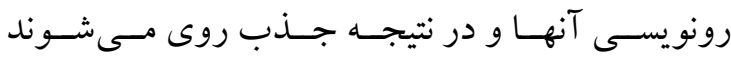
(Durmaz et al., 2011; Maser et al., 2001) بيان زنهاى bZIP در آزمايش حاضر در شرايط كمبود

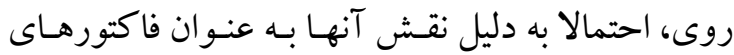
رونويسى در القاى بيـان زنهـاى ZIP اسـت. در تحقيـق

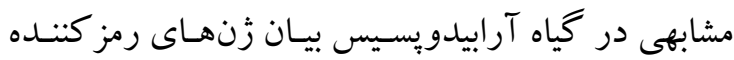
فاكتورهاى رونويسى AtbZIP19 و AtbZIP23 در شرايط كمبود روى نسبت بـه شـاهد، دو برابـر شـد، در حاليكهـ

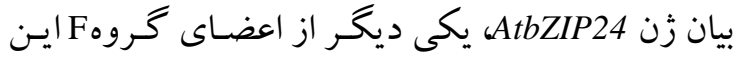

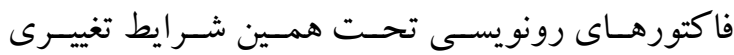
نداشـت (Assunção et al., 2010). نضـــ و همكـاران (Nazri et al., 2017)

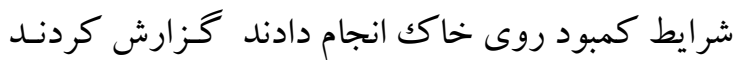

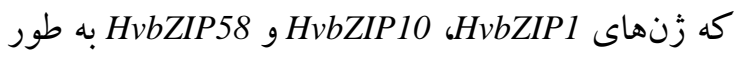

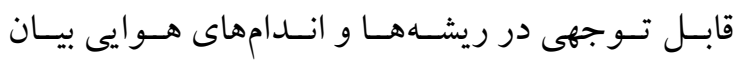

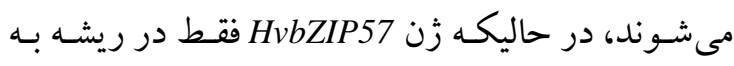

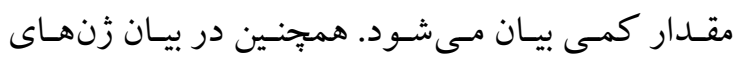

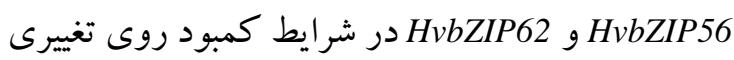

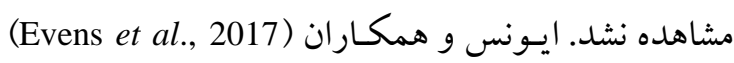



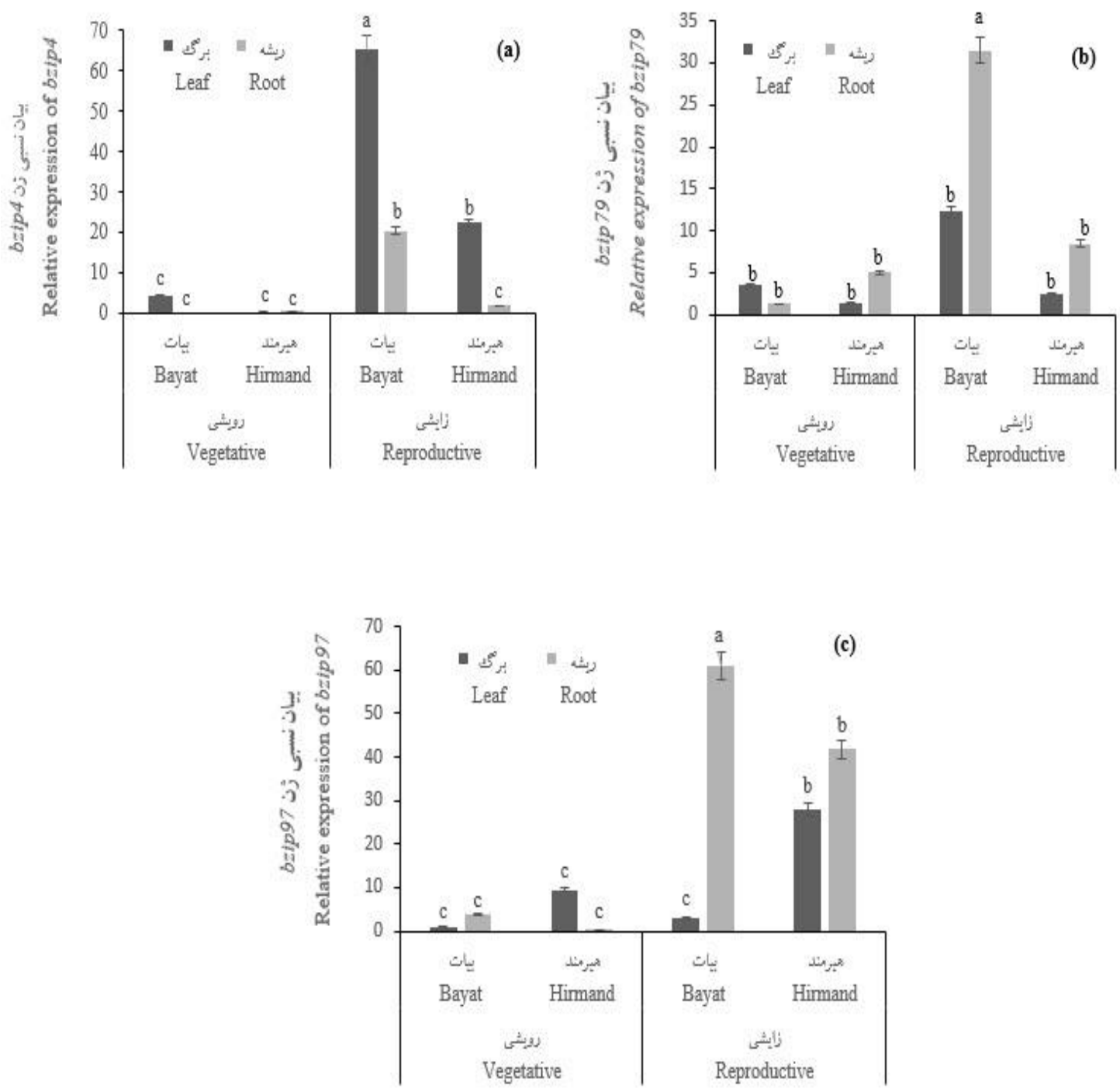

شكل ا- مقايسه ميانگين برهمكنش بافت × رقم × مرحله نمونهبردارى بر بيان زنهاى bZIP4 (a)، (b) bZIP79) و

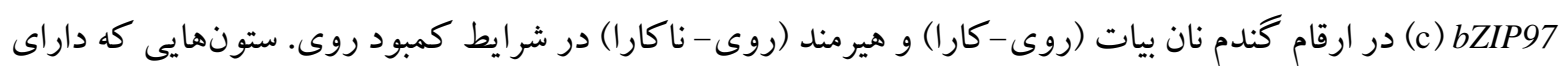

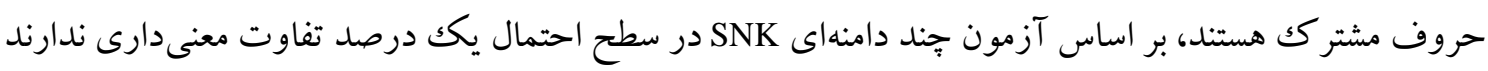
Fig. 1. Mean comparison for tissue $\times$ cultivar $\times$ sampling stage on the expression of bZIP4, bZIP79 and bZIP97 genes in Bayat (Zn-efficient) and Hirmand (Zb-inefficient) bread wheat cultivars under Zn deficiency conditions. Columns with similar letters are not significantly different at $1 \%$ probability level, using SNK multiple range test

بنـابر اين احتمـالا رونوشـتبـــــدارى ايسن فاكتورهــاى

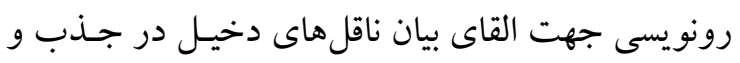

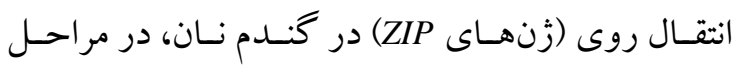
انتهايى دوره رشــ گيـاه (در مر حلـه سـنبلهدهى ) فعـال

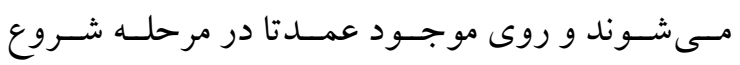

\section{نتيجه كيرى}

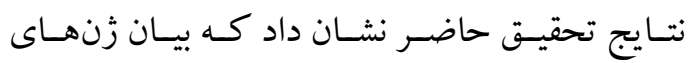

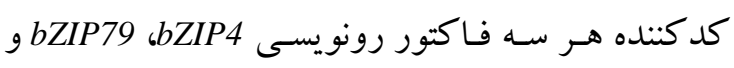

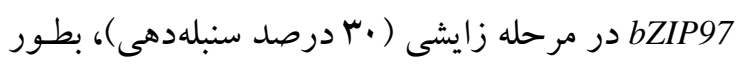

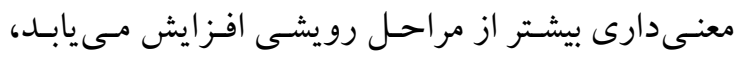




$$
\begin{aligned}
& \text { "نشريه علوم زراعى ايران"، جلد بيست و يكم، شماره F، زمستان 1هسا } \\
& \text { مى شود. }
\end{aligned}
$$

References

Ahmadi-Niari, A., A. Faramarzi, and D. Hassanpanah. 2013. Evaluation of drought tolerance indices for screening bread wheat genotypes in drought stress conditions. J. Curr. Eng. Allied Sci. 3(1): 23-27.

Alves, M. S., S. P. Dadalto, A. B. Gonçalves and G. B. De Souza. 2013. Plant bZIP transcription factors responsive to pathogens. Int. J. Mol. Sci. 14: 7815-7828.

Assunção, A. G., E. Herrero, Y. F. Lin, B. Huettel, S. Talukdar, C. Smaczniak and M. G. Aarts. 2010. Arabidopsis thaliana transcription factors bZIP19 and bZIP23 regulate the adaptation to zinc deficiency. PNAS, 107: 10296-10301.

Baghban-Tabiat, S. and M. H. Rasouli-Sadaghiani, M. 2012. Investigation of Zn utilization and acquisition efficiency in different wheat genotypes at greenhouse conditions. J. Sci. Tech. Greenhouse Cult. 3: 17-32. (In Persian with English abstract).

Bahari N., B. Bahari Bighdilu and L. Karpisheh. 2013. Evaluation of drought tolerance of bread wheat genotypes by stress and sensitivity tolerance indices. Ann. Biol. Res. 4(1): 43-47.

Cole, C. R., F. K. Grant, E. D. Swaby-Ellis, J. L. Smith, A. Jacques, C. A. Northrop-Clewes, K. L. Caldwell, C. M. Pfeiffer, and T. R. Ziegler, 2010. Zinc and iron deficiency and their interrelations in lowincome African American and Hispanic children in Atlanta. Am. J. Clin. Nutr. 91(4): 1027-1034.

Coleman, J. E. 1998. Zinc enzymes. Curr. Opinion Chem. Biol. 2: 222-234.

Durmaz, E., C. Coruh, G. Dinler, M. A. Grusak, Z. Peleg, Y. Saranga, T. Fahima, A. Yazici, L. Ozturk, I. Cakmak and H. Budak. 2011. Expression and cellular localization of ZIP1 transporter under zinc deficiency in wild emmer wheat. Plant Mol. Biol. Rep. 29(3): 582-596.

Evens, N. P., P. Buchner, L. E. Williams and M. J. Hawkesford. 2017. The role of ZIP transporters and group F bZIP transcription factors in the Zn-deficiency response of wheat (Triticum aestivum L.). Plant J. 92: 291-304.

Hwang, I., H. J. Jung, J. I. Park, T. J. Yang and I. S. Nou. 2014. Transcriptome analysis of newly classified bZIP transcription factors of Brassica rapa in cold stress response. Genomics, 104: 194-202.

Jakoby, M., B. Weisshaar, W. Droge-Laser, J. Vicente-Carbajosa, J. Tiedemann, T. Kroj and F. Parcy. 


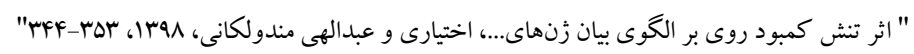

2002. bZIP transcription factors in Arabidopsis. Trend. Plant Sci. 7: 106-111.

Kasirajan, L., K. Boomiraj and K. C. Bansal. 2013. Optimization of genetic transformation protocol mediated by biolistic method in some elite genotypes of wheat (Triticum aestivum L.). Afric. J. Biotech. 12(6): 531-538.

Khavarinejad M. S. and A. V. Babajanov. 2011. Identification of relationships of quantitative and morphological traits to spring wheat genotype yields in drought levels of Mazandaran (north of Iran). Int. J. Agric. Sci. 1(6): 329-339.

Li, X., S., Gao, Y., Tang, F., Zhang, B., Feng, Z., Fang, L., Ma and C. Zhao. 2015. Genome-wide identification and evolutionary analyses of bZIP transcription factors in wheat and its relatives and expression profiles of anther development related TabZIP genes. BMC Genomics. 16: 1-21.

Marschner, H. 1995. Mineral Nutrition of Higher Plants. Academic Press, London, UK.

Maser, P., S., Thomine and J. I. Schroeder. 2001. Phylogenetic relationships within cation transporter families of Arabidopsis. Plant Physiol. 126: 1646-1667.

Mason, J. B. and M. Garcia. 1993. Micronutrient deficiency-the global situation. SCN News. 9: 11-16.

Nakabayashi, R. and K., Saito. 2015. Integrated metabolomics for abiotic stress responses in plants. Curr. Opin. Plant Biol. 24: 10-16.

Nazri, A. Z., J. H. C., Griffin, K. A., Peaston, D. G. A., Alexander-Webber and L. E., Williams. 2017. Fgroup bZIPs in barley-a role in Zn deficiency. Plant Cell Environ. 40: 2754-2770.

Sakal, R., A. P., Singh and R. B. Sinha. 1988. Effect of different soil fertility levels on response of wheat to zinc application on calciorthent. J. Indian Soc. Soil Sci. 36: 125-127.

Welch, R. M., and R. D. Graham. 1999. A new paradigm for world agriculture: meeting human needs: productive, sustainable, nutritious. Field Crops Res. 60(1): 1-10. 


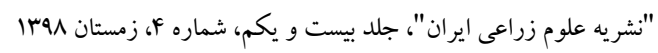

\title{
Effect of Zn deficiency stress on expression pattern of genes encoding bZIP4, bZIP79 and bZIP97 transcription factors in bread wheat (Triticum aestivum L.) cultivars
}

\author{
Ekhtiyari, M. ${ }^{1}$ and B. Abdollahi Mandoulakani ${ }^{2}$
}

\begin{abstract}
Ekhtiyari, M. and B. Abdollahi Mandoulakani. 2020. Effect of $\mathrm{Zn}$ deficiency stress on expression pattern of genes encoding bZIP4, bZIP79 and bZIP97 transcription factors in bread wheat (Triticum aestivum L.) cultivars. Iranian Journal of Crop Sciences. 21(4): 344-353. (In Persian).
\end{abstract}

A factorial experiment (based on completely randomized design) with three replications was conducted in faculty of agriculture of Urmia University, Iran in 2016 to investigate the effect of soil $\mathrm{Zn}$ deficiency on the expression of genes encoding bZIP4, bZIP79 and bZIP97 transcription factors in Zn-efficient and Zn-inefficient bread wheat cultivars. Cv. Bayat (Zn-efficient) and cv. Hirmand (Zn-inefficient) were grown under soil Zn deficient and Zn sufficent conditions. The expression levels of three above-mentioned transcription factors were measured using Real time PCR technique in leaf and root of the cultivars at two growth stages; beginning of stem elongation (vegetative) and 30\% of heading (reproductive). Analysis of variance showed that the interaction effect of cultivar $\times$ tissue $\times$ sampling time was significant on the expression of three studied genes. The mean comparison revealed that the highest expression level of bZIP4 (more than 65 fold change) in the leaf of Zn-efficient cultivar (Bayat) at vegetative stage under $\mathrm{Zn}$ deficiency conditions. The highest expression of bZIP79 and bZIP97 genes (more than 31 and 60 fold change, respectively) observed in the root of Bayat cultivar at vegetative stage under $\mathrm{Zn}$ deficiency conditions. No significant difference was found between $\mathrm{Zn}$-efficient and Zn-inefficient cultivars for the expression level of three studied genes at the vegetative stage. Considering the significant increase in expression of all studied genes at vegetative stages, it may be concluded that the mRNA transcription of the transporter genes involved in $\mathrm{Zn}$ uptake and translocation (ZIP genes), are activated at the heading stage of the two bread wheat cultivars. Moreover, according to the increased expression of bZIP4 in leaf, and bZIP79 and bZIP97 in root, the possible role of bZIP4 and bZIP79, and bZIP97 might be the transcriptional activation of ZIP genes involved in $\mathrm{Zn}$ translocation within the plant and $\mathrm{Zn}$ uptake from soil, respectively, under soil Zn deficiency conditions.

Key words: Bread wheat, $b Z I P$ transcription factor, Gene expression, Real time PCR and Zn deficiency.

\footnotetext{
Received: February, 2019 Accepted: September, 2019

1. MSc Student, Urmia University, Urmia, Iran

2. Associate Prof., Urmia University, Urmia, Iran (Corresponding author) (Email: b.abdollahi@urmia.ac.ir)
} 